УДК 34.03

ПЕЩЕРОВ Георгий Иванович - доктор военных наук, профессор, академик Академии военных наук; ведущий научный сотрудник Научно-исследовательского института Федеральной службы исполнения наказаний России (125130, Россия, г. Москва, Нарвская ул., 15A, стр. 1; georgiy-p@yandex.ru)

\title{
ВЗАИМОСВЯЗЬ ПРЕСТУПНОСТИ И СОЦИАЛЬНО-ПОЛИТИЧЕСКИХ УСЛОВИЙ В ОБЩЕСТВЕ: РОССИЙСКИЙ ОПЫТ
}

\begin{abstract}
Аннотация. В процессе эволюционного развития человеческого общества преступность как негативное явление неразрывно сопровождала его, увеличиваясь в период смут (революции, перевороты и т.д.) и снижаясь в спокойные и мирные времена. По результатам исследования выявлено, что основные всплески преступности происходят в периоды социально-политических трансформаций (глубокие реформы в стране, революции, периоды социально-политических преобразований и др.); в условиях закономерной тенденции к гуманизации системы исполнения наказания в человеческом обществе; в условиях ухудшения социально-экономического положения населения страны и др. Актуальность исследования взаимосвязи преступности и социально-политических условий в российском обществе обусловлена ростом преступности в стране в связи с происшедшей социально-политической и экономической трансформацией общества и необходимостью выявления закономерностей ее изменения.

Ключевые слова: динамика преступности, социальный климат в обществе, периоды социально-политической и экономической трансформации общества, консервативное и либеральное правление, развитие преступности
\end{abstract}

$\mathrm{O}$ бщеизвестен исторический факт, что уровень преступности в человеческом обществе - величина непостоянная, периодически меняющаяся в зависимости от факторов среды обитания. Происходящие социально-политические и экономические процессы в обществе достаточно динамичны, и их изменения напрямую отражаются и на росте преступности в стране. Поскольку снижение преступности и сохранение благоприятного социального климата в обществе для гармоничного развития личности и общества в целом - задача государственной важности, необходимо изучать как преступность в целом, так и факторы, влияющие на динамику преступности.

Внутренняя политика Российского государства на протяжении многовековой истории была направлена на поддержание общественного спокойствия и правопорядка в стране и являлась одним из механизмов регулирования социального климата в обществе. При этом преступность, напрямую зависящая от социально-политических и экономических условий в стране, является весомым фактором, оказывающим значительное влияние на социальный климат в обществе. Исходя из этого, анализ динамики преступности в обществе позволяет наглядно продемонстрировать изменение социального климата в различные периоды истории России. К сожалению, статистические данные о преступности в Древней Руси, а также в переходный период от монархии к республиканской форме правления отрывочны и неполны, поэтому автор вынужден оперировать сохранившимися относительными историческими данными и данными более позднего периода истории России (см. рис. 1, 2, 3).

Сохранившиеся в истории статистические данные о преступности показывают, что абсолютное число зафиксированных преступлений с 1800 по 1913 г. возросло почти в 12 раз, но с учетом роста численности населения в стране - 
всего в 3 раза ${ }^{1}$. При этом в исторический период до отмены крепостного права преступность имела тенденцию к снижению, а после 1861 г. - к повышению, что обусловливается кардинальным изменением социально-экономических и политических условий в стране, значительно осложнивших жизнедеятельность населения [Остроумов 1980: 15].

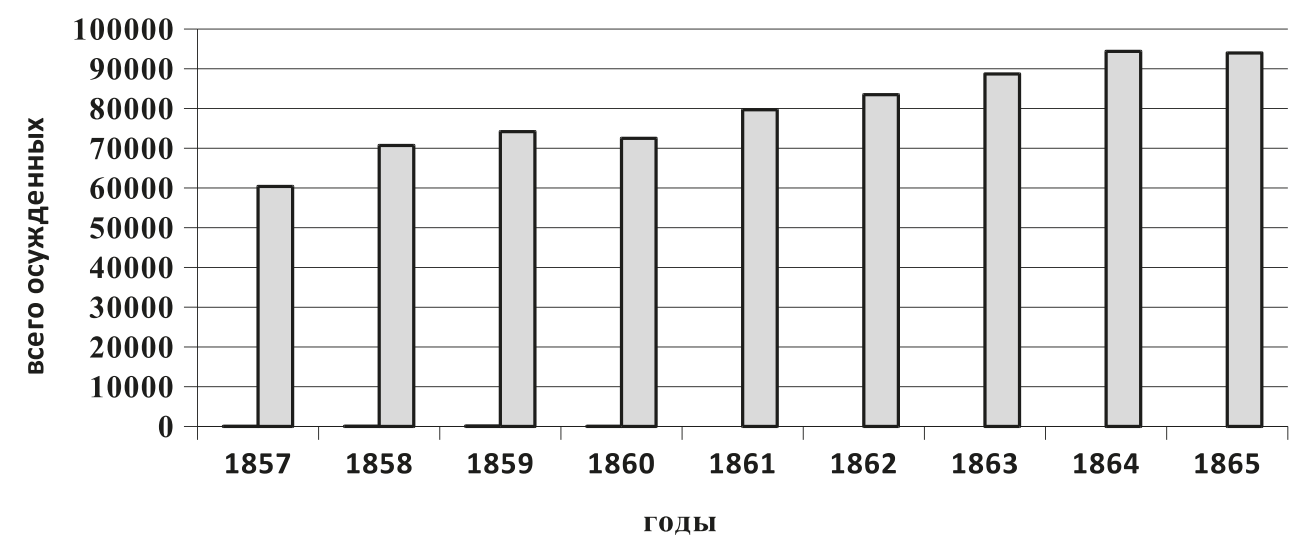

Рисунок 1. Динамика колебаний преступности по годам в Российской империи $(1857-1865$ гг.)

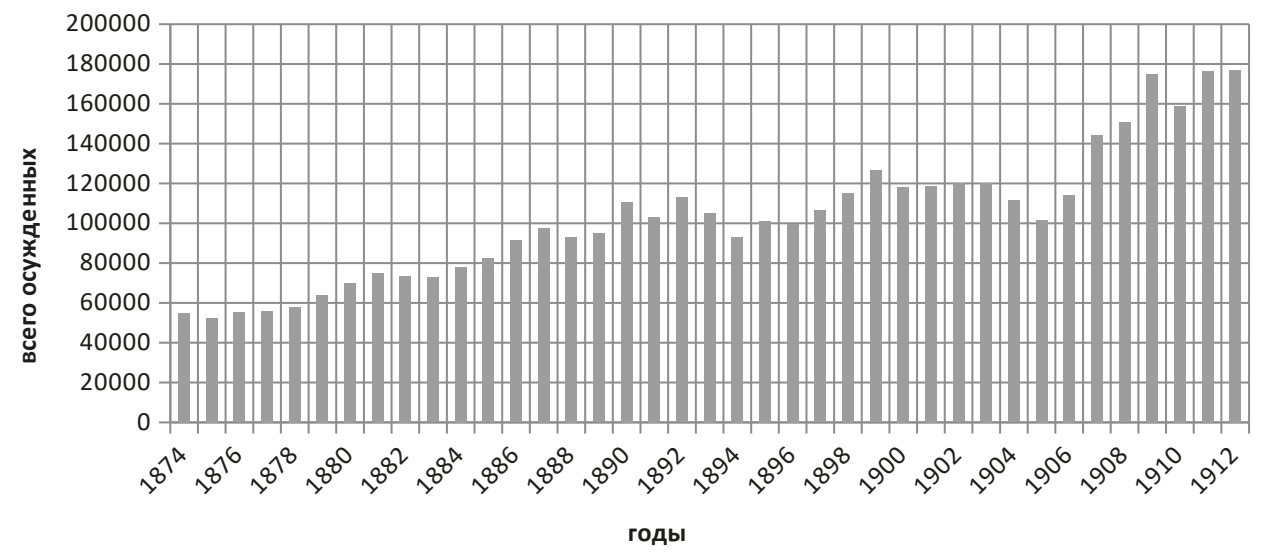

Рисунок 2. Динамика колебаний преступности по годам в Российской империи (1874-1912 гг.).

Индекс преступности в стране в данный период времени вырос почти в 3 раза, поскольку недовольный народ бунтовал и совершал различные преступления ${ }^{2}$. В дальнейшем преступность непрерывно возрастала (с недолгой стабилизацией в 1890-е гг.), подчиняясь многочисленным факторам окружающей действительности. К одному из немаловажных факторов относится влияние личности правителя государства, политическая воля которого способна вершить судьбы многомиллионного народа, и которое может стать

\footnotetext{
1 Статистика осужденных в СССР за 1926 г. ЦСУ СССР. М. 1928.

2 Тарновский Е.Н. 1909. Движение преступности в Российской империи за 18991908 гг. - Журнал Министерства юстищии. № 9. С. 57.
} 
определяющим в процессе поддержания благоприятного социального климата в стране.

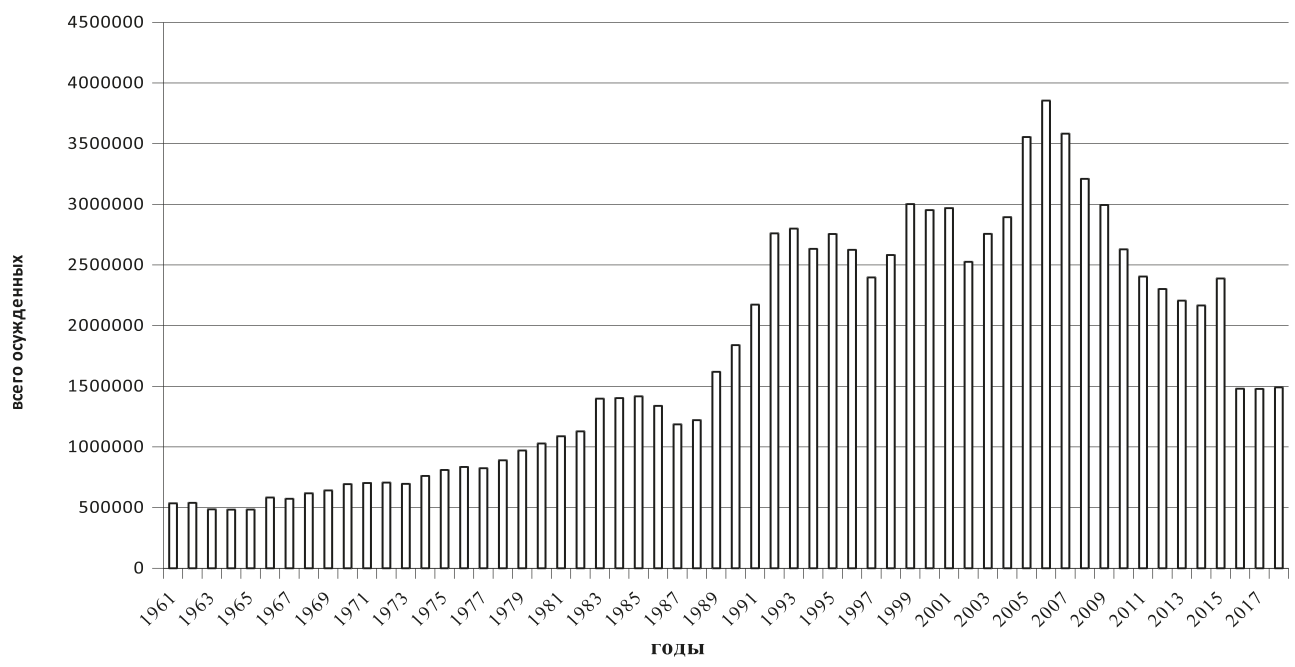

Рисунок 3. Динамика колебаний преступности в разные периоды в СССР и России (1961-2020 гг.).

Как отмечают историки, преступность в России в недалеком прошлом имела следующую интересную динамику:

- возрастала в либеральное правление Александра I;

- уменьшалась при консервативном правлении Николая I;

- почти в 3 раза возросла в реформаторскую эпоху Александра II;

- уменьшилась при консервативном правлении Александра III;

- выросла более чем на $50 \%$ при противоречивом и неустойчивом правительственном курсе Николая II.

Парадокс? Нет. Это закономерный процесс, обусловленный нарушением социального баланса между населением и верхушкой власть имущих. При этом минимальный уровень преступности в России был зафиксирован в конце правления Николая I, а максимальный ее уровень обозначился в 1913 г. Во время Первой мировой войны, в 1914-1916 гг, преступность в целом по стране снизилась примерно на 30\%, но с 1916 г. вновь обнаружилась тенденция к ее повышению ${ }^{1}$. Здесь проявляется закономерность развития человеческого общества: в период вооруженных конфликтов и войн, когда наиболее активная часть населения занята военными действиями, уровень преступности в стране снижается.

Таким образом, динамика преступности в исследуемый период имела явно циклический характер, причем чем консервативнее было правление и чем тверже проводилась внутренняя политика, тем ниже была преступность, и наоборот, чем мягче была внутренняя политика и либеральнее правительственный курс, тем преступность была выше. Консервативная политика, как правило, сопровождалась не только усилением репрессий против нарушителей закона, но и ужесточением контроля за поведением населения, что оставляло меньше места для бесконтрольных проступков и вследствие этого сдерживало проявления девиантного поведения, в т.ч. и криминального.

\footnotetext{
1 Население России за 100 лет (1897-1997): статистический сборник. М. 1998. С. 30-32.
} 
Напротив, ослабление контроля провоцировало импульсы к нарушению установленного законного порядка. Поскольку либеральные и консервативные правительственные курсы, как правило, чередовались, то это, вероятно, и порождало цикличность в динамике преступности, которую мы наблюдаем в течение всего XIX в. При Николае II цикличность колебаний преступности изменилась, противоречивая государственная политика в 1895-1917 гг. способствовала росту преступности. В результате это привело к росту криминального поведения в обществе, брожение масс достигло своего критического значения, и впоследствии это привело к возникновению революционной ситуации.

В то же время, если рассматривать детально сферу преступности, доля раскрытых преступлений в 1913 г. повысилась более чем на 60\%. Увеличению раскрываемости преступлений, по-видимому, способствовал научно-технический прогресс (применение дактилоскопии, распространение фотографии, появление современных средств информации, рост профессионализма детективов, усовершенствование системы сыска и т.д.).

Число подсудимых в абсолютных и относительных цифрах до конца XIX в. в целом изменялось синхронно с числом уголовных дел. Но с начала XX в. число подсудимых стало увеличиваться быстрее. Причина в том, что в начале XX в. увеличилось число преступлений в соответствии с действующим законодательством, куда входили антиправительственные манифестации, стачки, а также религиозные преступления. Запрещенные до 1905 г., но имевшие массовый характер, они и обусловили увеличение числа подсудимых. Чрезмерная политизация общества при определенных ограничениях гражданских прав послужила стержневым фактором возрастания массового противоправного поведения населения. В целом, для данного периода характерно уменьшение доли коллективных преступлений на $15 \%$, что, возможно, свидетельствует о развитии индивидуализма среди профессиональных преступников.

Число осужденных в исследуемый период изменялось также в основном параллельно с другими показателями преступности. Минимальное число осужденных зафиксировано в 1850-е гг., а максимальное - в 1913 г. В данный период процент оправданных имел тенденцию к увеличению. Если после судебной реформы 1864 г. большой процент оправданных можно объяснить либеральными настроениями, превалировавшими в обществе, то как объяснить еще более низкий процент осужденных? Например, в 1800-1860 гг. были оправданы более $50 \%$ подсудимых. На самом деле объяснение очень простое. Во-первых, полиция до 1860-х гг. имела широкие права арестовывать всех лиц, подозреваемых в совершении преступления, действуя по принципу «лучше задержать невиновного, чем упустить виновного». Отсюда число преступлений было неадекватно числу задержанных, а значит и подсудимых. Во-вторых, институт профессиональных следователей в России возник только в 1860 г. и достиг заметного прогресса в начале XX в., что сказывалось на раскрываемости преступлений, на возможности собрать достаточно улик, чтобы доказать виновность подозреваемого. Вместе с тем низкий процент осужденных доказывает, что судьи стремились объективно подходить к делу, и при отсутствии достаточных улик они оправдывали подозреваемого. Это говорит о том, что закон и правосудие не были пустым звуком даже в те далекие времена в царской России [Остроумов 1980: 15].

За период с 1917 по 1922 г. имеются лишь отрывочные данные о состоянии преступности, поскольку сложная социально-политическая и экономическая ситуация в стране не позволяла вести строгие статистические обзоры в исследу- 
емой области ${ }^{1}$. Более того, в переходный период, когда кардинально меняется законодательная и правовая база государства, сложно оценивать само понятие преступности. В силу сложившейся политической обстановки возникла ситуация, когда арестанты пересели в кресла, а власть имущие ушли в лагеря.

В период восстановления народного хозяйства и нэпа (1922-1925 гг.) не наблюдается какая-либо выраженная тенденция изменения числа осужденных. Данные о числе зарегистрированных преступлений говорят о снижении преступности в 1922 г., которое затем сменилось ее ростом в 1924-1925 гг. Отмечается тенденция к урбанизации преступности, перемещению ее в крупные города, росту числа должностных преступлений и снижению числа хозяйственных (часть из которых в период нэпа была легализована). В целом картина преступности схожа с периодами перед Первой мировой войной и перед экономическими реформами 1990 гг. Рассматриваемый период оценивается специалистами-криминологами как относительно благополучный, характеризующийся снижением преступности в стране 2 .

В период индустриализации (1926-1929 гг.) увеличивается число зарегистрированных преступлений, однако ввиду прироста численности населения коэффициент преступности снижается. Понятно, что сведения за первые годы советской власти неполны и отрывочны (по отдельным губерниям) в силу реорганизационных процессов в государстве. В те же годы быстро растет и профессиональная преступность, закладывается фундамент организованной преступности (в 1920-е гг. - в виде банд, с начала 1930-х гг. - в виде сообщества «воров в законе»). С 1925 по 1928 г. имеются данные в целом по СССР, в соответствии с которыми по явно завышенным данным (по мнению специалистов, производился многочисленный учет, который и внес ошибки в общую статистику) были осуждены около 3 млн чел. ${ }^{3}$

В период с 1930 по 1940 г. статистические данные о числе осужденных подтверждают довольно существенное снижение числа лиц, находящихся в местах лишения свободы [Шамсунов, Пещеров 2017]. Видимо, идеологический подъем в стране, призыв молодежи к освоению воздушного пространства и другие мероприятия Коммунистической партии сыграли свою позитивную воспитательную роль.

Общеуголовная преступность в годы Великой Отечественной войны обусловливалась особенностями военного времени. При этом если в 1941-1942 гг. отмечалось возрастание числа осужденных по указам военного времени и осужденных военными трибуналами, то с 1943 г. численность данных категорий преступлений уменьшается [Зубков 2000]. Здесь также проявляется особенность жизнедеятельности общества в военное время, когда основная масса мужского населения находится на фронте.

В послевоенные годы наблюдался рост преступности, причинами которого явились послевоенная разруха, бездомность, беспризорность, социальная дезадаптация демобилизованных лиц в совокупности с оседанием у населения трофейного огнестрельного оружия. Свою негативную роль сыграли также проводившиеся во второй половине 1950 гг. недостаточно продуманные амнистии, позволившие освободить значительную часть рецидивистов и професси-

\footnotetext{
1 Преступность и репрессии в РСФСР: сборник статистических сведений по Союзу ССР, 1918-1923 гг. Т. ХVIII. 1925. М.: ЦСУ РСФСР. 1930.

2 Сборник судебной статистики СССР за 1935 г. М. 1937; Статистика осужденных в СССР в 1923-1924 г2. М.: ЦСУ СССР. 1927; Статистика осужденных в СССР в 1925, 1926, 1927 г2. М.: ЦСУ СССР. 1930.

3 Итоги десятилетия Советской власти в цифрах, 1917-1927 г2. М.: ЦСУ. Отд. 4. 1928; Статистика осужденных в РСФСР за 1928-1934 г2. М. 1935.
} 
ональных преступников из мест отбывания наказаний, что значительно усложнило социальные условия в стране [Детков 1999].

В конце 1950 гг. принимаются новые общесоюзные Основы уголовного законодательства, которые стали новым либеральным направлением в системе регулирования социального климата в обществе. В частности, они предусматривали возможность освобождения от уголовной ответственности в связи с применением мер общественного воздействия, например передачей на поруки, направлением материалов в товарищеский суд, в комиссию по делам несовершеннолетних и т.д. Результатом введения данных мер явилось снижение числа осужденных и увеличение доли оправданных ${ }^{1}$. Наблюдается снижение числа преступлений в периоды хрущевской «оттепели» (1963-1965 гг.) и горбачевской перестройки (1986-1988 гг.), когда изменение социально-политических и экономических условий способствовало нормализации социального климата в обществе ${ }^{2}$. То, что это не случайность, подтверждается позитивной динамикой в те же годы других социальных показателей (снижение уровня самоубийств, смертности, повышение рождаемости и др.) [Ли 1997: 121-122].

Наблюдается резкий рост зарегистрированной преступности в 1989-1993 гг. (более чем в 2 раза). Это объясняется периодом бурных социально-экономических и политических перемен при сохранении глубокого всестороннего кризиса в стране, когда катастрофическое обнищание народа вкупе с идеологическим крахом спровоцировало всплеск преступности [Лунеев 1997: 60; 2003].

Дальнейшее возрастание преступности наблюдается в 1998-2005 гг., когда уровень общей преступности увеличился почти в 1,5 раза, причинение тяжкого вреда здоровью - в 1,2 раза, разбойные нападения - в 1,6 раза и т.д.). Причина также заключалась в затяжном экономическом кризисе и социально-политической нестабильности в стране: население устает ждать перемен к лучшему и переходит грань дозволенного в целях повышения собственного благосостояния ${ }^{3}$ [Преступность в России... 2004: 120-123].

В дальнейшем, в 2010-2020 гг., происходит постепенное снижение числа преступлений, и особенно снижение числа осужденных (по состоянию на 1 января 2021 г. в России насчитывается 378 тыс. осужденных), обусловленное такими факторами, как стабилизация социально-политического положения в стране и целенаправленная политика оздоровления общества 4 . Как позитивную тенденцию в этот период можно отметить интенсификацию трудового воспитания среди осужденных, что позволило довести объем производства товаров и услуг, например в 2016 г., почти до 54 млрд руб. ${ }^{5}$

Перед человечеством стоит сложнейшая задача - снижение уровня преступности и сохранение благоприятного социального климата в человеческом обществе. Однако каждое государство по-своему подходит к решению данной

\footnotetext{
1 Состояние и тенденции преступности в Российской Федерации: криминологический и уголовно-правовой справочник (под общ. ред. А.Я. Сухарева, С.И. Гирько). М.: Экзамен. 2007. C. 60-65.

${ }^{2}$ С 1961 по 1978 гг. - авторские расчетные данные. Источники: ежегодники «Преступность и прравонарушения». М.: МВД РФ; МЮ РФ.

3 Латентная преступность в Российской Федерации за 2001-2002 ге.: статистический сборник. М.: Российская правовая академия МЮ РФ. 2004; Состояние преступности в России за январь-декабрь 2019 года. М.: МВД РФ: ФКУ ГИАЦ. 2021; Интернет-сайт МВД РФ.

4 Состояние преступности в России за январь-декабрь 2020 года. М.: МВД РФ: ФКУ ГИАЦ. 2021; Интернет-сайт МВД.РФ.

5 Официальный сайт службы государственной статистики - Росстат. 2021. Доступ: www.gks.ru; Портал правовой статистики. Генеральная Прокуратура Российской Федерации. 2021. Интернет-сайт crimestat.ru; Состояние преступности в России за январь-декабрь 2019 года. М.: МВД РФ: ФКУ ГИАЦ. 2021; Интернет-сайт МВД.РФ.
} 
задачи, как правило, путем назначения наказания соразмерно тяжести совершенного преступления. При этом, конечно же, учитываются личные характеристики виновного, все обстоятельства дела и много других нюансов, чтобы наказание смогло, по возможности, послужить целям исправления и предупреждения [Преступность в России... 2004: 120-123]. Таким образом, получается, что цель исправления будет достигнута наряду с целью превенции и одновременно - восстановления социальной справедливости.

Эволюция развития законодательной базы практически во всех странах мира показывает тенденцию к гуманному отношению к отбывающим наказание в исправительных учреждениях. Однако представляется, что эта гуманность провоцирует человека на совершение преступления. По всей видимости, это одна из причин ежегодного увеличения числа правонарушений в человеческом обществе во многих государствах. Существует также закономерность роста преступности, как ни странно, в экономически развитых странах мира (США занимают 1-е место в мире по уровню преступности). Применяемая практически во всех странах тюремная система на самом деле является не самым рациональным способом решения проблемы регулирования социального климата в обществе. Опыт России, Советского Союза и некоторых зарубежных стран (Япония, США и др.) наглядно показывает рациональность использования системы трудового воспитания, что на самом деле может позитивно повлиять на развитие экономики, исправление осужденных и снижение уровня преступности в стране.

\section{Список литературы}

Детков М.Г. 1999. Тюрьмы, лагеря и колонии России: монография (под ред. Я.В. Крашенинникова). М.: Вердикт-1М. 448 с.

Зубков А.И. 2000. Карательная политика России на рубеже тысячелетий. М.: Penal Reform International. $83 \mathrm{c}$.

Ли Д.А. 1997. Преступность как социальное явление. М.: ИИА «Русский мир». $174 \mathrm{c}$.

Лунеев В.В. 1997. Преступность ХХ века. М.: Норма. 497 с.

Лунеев В.В. 2003. Особенности современной преступности в России. Куда пришла Россия? Итоги социетальной трансформации (под общ. ред. Т.И. Заславской). М.: Изд-во МВШСЭН. С. 263-271.

Остроумов С.С. 1980. Преступность и ее причины в дореволюционной России. М.: Изд-во МГУ. 204 с.

Преступность в России начала XXI века и реагирование на нее (отв. ред. А.И. Долгова). 2004. М.: Российская криминологическая ассоциация, 12 Центральная типография МО РФ. 123 с.

Шамсунов С.Х., Пещеров Г.И. 2017. Динамика уровня преступности в различные периоды России и ее влияние на климат в обществе: монография. Тверь: ФКУ ФСИН России. 164 с. 
PESHCHEROV Georgy Ivanovich, Dr.Sci. (Mil.Sci.), Professor, Academician of the Academy of Military Sciences, Leading Researcher at the Research Institute of the Federal Penitentiary Service of Russia (bld. 1, 15a Narvskaya St, Moscow, Russia, 125130; georgiy-p@yandex.ru)

\title{
THE RELATIONSHIP BETWEEN CRIME AND SOCIO-POLITICAL CONDITIONS IN SOCIETY: RUSSIAN EXPERIENCE
}

\begin{abstract}
In the process of the evolutionary development of human society, crime, as a negative phenomenon, inseparably has accompanied it, increasing during unrest (revolutions, coups, etc.) and decreasing in calm and peaceful times. According to the results of the study, the author reveals that the main bursts of crime occur during periods of socio-political transformations in human society (deep reforms in the country, revolutions, periods of socio-political transformations, etc.); in the context of a natural tendency towards the humanization of the punishment system in human society; in conditions of deterioration in the socio-economic situation of the country's population, etc.

The relevance of the study of the relationship between crime and socio-political conditions in Russian society is due to the growth of crime in the country in connection with the socio-political and economic transformation of Russian society and the need to identify the patterns of its change.

Keywords: dynamics of crime, social climate in society, periods of socio-political and economic transformation of society, conservative and liberal government, development of crime
\end{abstract}

АБАКУМОВА Екатерина Александровна - кандидат исторических наук, методист отдела регламентации образовательной деятельности Курского государственного университета (305000, Россия, г. Курск, ул. Радищева, 33; abakumova64@yandex.ru)

\section{ВОЗНИКНОВЕНИЕ ГОРОДОВЫХ КАЗАКОВ КАК КАТЕГОРИИ СЛУЖИЛЫХ ЛЮДЕЙ}

\begin{abstract}
Аннотация. Формирование городовых казаков как категории государственных служилых людей по прибору на Руси XIV-XVII вв. тесно связано с укреплением юго-восточной окраины Русского государства. Городовые казаки несли гарнизонную и пограничную службу на укрепленных («засечных») линиях. Автор дает характеристику военной службы городовых казаков, а также рассматривает их социальный состав. Ключевые слова: дружина, народное ополчение, служилые люди, городовые казаки, сторожевая служба, устав
\end{abstract}

И сторическое развитие вооруженных сил Русского государства до преобразований Петра Великого представляло собой постепенную смену нескольких систем, которые соответствовали каждому особому типу или виду войск. Такими основными типами войск были: народное ополчение, дружина, поместные войска, постоянное войско и наемное (иноземное) войско.

Народное ополчение было господствующим типом русских войск в первоначальную эпоху вечевого периода нашей истории. С постепенным развитием княжеской дружины народное ополчение стало созываться редко и стало играть второстепенную роль. Впоследствии, с утверждением на Руси единовластия, участие городских и сельских жителей в обороне государства вновь развивается, причем это выражалось не в виде поголовного вооружения всего 